\title{
Eternamente vive quien muere por la patria. El Centenario de los Mártires, Tunja, Colombia (1916)
}

\author{
Abel Fernando Martinez Martin* \\ Andrés Ricardo Otálora Cascante ${ }^{* *}$
}

Recibido el 7 de octubre de 2017; aceptado el 19 de diciembre de 2017

\begin{abstract}
In Tunja's celebration of centennial decade of national independence (19101919), its stands out the centenary of Heroes-martyrs in 1916, characters of the first republic, executed in the city in the reconquest (1816). With this reason, civil and ecclesiastical authorities organized a patriotic party coordinated by the Academy of History, that included parades, openair mass, literary contests, industry expos and the exhumation of the martyrs' bodies and their move to the cathedral. The speeches, the corporeity of the martyrs, the exaltation of the values like progress and modernity were the fundamental feature of this centenary, linked to the Hispanic tradition of the city.
\end{abstract}

Key words: Centenary of heroes-martyrs, patriotic party, Nation building, Tunja, Colombia.

* Md. Doctor en Historia y Magíster en Historia de la Universidad Pedagógica y Tecnológica de Colombia (UPTC) en Tunja. Profesor asociado, Escuela de Medicina UPTC. Director del Grupo de Investigación Historia de la Salud en Boyacá-UPTC, director del Museo de Historia de la Medicina y la Salud-UPTC, correo electrónico: abelfmartinez@gmail.com

** Od. Esp. Antropología forense, Magíster en Antropología y Doctor en Historia por la Universidad Nacional de Colombia en Bogotá. Investigador del Grupo Historia de la Salud en Boyacá-UPTC en Tunja, correo electrónico: arotalorac@unal.edu.co 


\section{RESUMEN}

En la celebración de la década de los Centenarios de la Independencia nacional (1910-1919) en Tunja, Colombia, se destaca el centenario de los héroes-mártires en 1916, personajes de la primera república fusilados en la ciudad durante la reconquista (1816). Las autoridades civiles y eclesiásticas organizaron la fiesta patriótica coordinada por el centro de historia con desfiles, misas, juegos florales, exposiciones y la exhumación de los huesos de los mártires que son trasladados a la Catedral. Los discursos, la corporeidad de los mártires, la exaltación de valores como el progreso y la modernidad caracterizan este centenario que se liga a la tradición hispánica de la ciudad.

Palabras clave: Centenario de los héroes-mártires, fiesta patria, construcción de la Nación, Tunja, Colombia.

\section{INTRODUCCIÓN}

$\mathrm{L}$

a Independencia en América desde mediados del siglo XIX se había convertido - siguiendo a Anderson - en una herencia que como tal, tenía que entrar en una serie genealógica. La articulación de los movimientos nacionales descansaba en el lenguaje común y, con ello, religión y cultura común con la antigua metrópoli que habían hecho posible las primeras imágenes nacionales. La continuidad con el pasado colonial $^{1}$ del que eran deudoras a través de la lengua, garantizaba no sólo la genealogía histórica, sino también la legitimación del poder que hacían suyo en los actos oficiales utilizando el discurso de la historia patria. ${ }^{2}$

Los centenarios de 1910 a 1924, a lo largo de América Latina, se vieron atravesados por esta reconciliación y revaloración del pasado colonial. En Venezuela, la delegación española fue encabezada por el nieto del "Pacificador" Pablo Morillo, máximo ejemplo de perdón y olvido. Allí como en México, Argentina, Chile o Colombia, las celebraciones no hicieron referencia a los hechos más sangrientos de los combates independentistas, más bien, aludieron a España como madre y fuente de la civilidad de las naciones americanas y de la

1 En Colombia la historiografía denomina al periodo comprendido entre el fin de la conquista y el inicio de la Independencia (siglo XVI, XVII, XVIII e inicios del XIX) como época colonial o simplemente la Colonia, la cual se subdivide en dos periodos, el Colonial temprano que corresponde a la monarquía de los Austrias, y el tardío, al reinado de la dinastía Borbón en el trono peninsular. Tovar Zambrano, La Historiografía colonial, pp. 21-117. Así mismo, en la historia del Arte colombiano y la historia de la Medicina y la Salud, temas que trabajan los autores, la categoría es generalmente usada.

2 Anderson, Comunidades Imaginadas. Reflexiones sobre el origen y la difusión del nacionalismo, p. 273. 
creación de las comunidades colectivas de la Nación, ${ }^{3}$ entrando las repúblicas a la segunda década del siglo xx reconciliadas con el pasado colonial. ${ }^{4}$

En este marco, en la segunda década del siglo xx, se celebraron los centenarios de la Independencia nacional de Colombia, en los cuales la pequeña y andina ciudad de Tunja tuvo una oportunidad festiva, social y urbanística única. Nunca antes, como hasta ese momento, la sociedad de la ciudad y del departamento de Boyacá, del que es capital, se habían sentido tan deudoras de la gratitud nacional y nunca, como hasta entonces, la oportunidad del progreso, que llegaba con la higienización de los espacios públicos, la construcción de acueductos, la macadamización de las calles, la instalación de la luz eléctrica, el señalamiento de las actividades industriales, la construcción de plazas, palacios de exposiciones, parques, monumentos, obras de beneficencia, columnas, bibliotecas y museos, pero, sobre todo, el sueño de ver sobre sus verdes campos el vapor de la modernidad, jalado por la locomotora del anhelado ferrocarril del nordeste, habían sido tan cercanos.

La sociedad, en cabeza de dos instituciones, la eclesiástica y poderosa diócesis de Tunja y la civil y conservadora gobernación de Boyacá, se aprestó a exaltar los valores de los héroes, ya míticos, tras un siglo de Independencia. ${ }^{5}$ Como afirma Martínez: se trató de un juramento organizado de fidelidad a los dioses tutelares de la república conservadora: la iglesia y los próceres. ${ }^{6}$ En efecto, como afirma Rodríguez, "todos estos actos estuvieron tutelados por las autoridades eclesiásticas. No sólo porque los ritos esenciales se hacían en las iglesias y catedrales, sino porque los gobernantes del Estado casi se veían supeditados a los religiosos. [...] En el caso colombiano, [...] el pacto EstadoIglesia se conservó en la República de una manera casi inalterada". ${ }^{7}$

Estas celebraciones se dieron en el marco de un constante llamado que se hacía por parte del estado nacional y la iglesia católica — fortalecida tras el

3 Earle, "Padres de la Patria and the Ancestral Past: Commemorations of Independence in Nineteenth- Century Spanish America", pp. 801-805.

4 A excepción del caso mexicano, donde la Revolución dio origen al régimen que celebraría la consumación de la Independencia en 1921 y buscaría el reconocimiento del pasado prehispánico como base de la nacionalidad. Lempérière, "Los dos Centenarios de la Independencia Mexicana (1910 y 1921). De la Historia Patria a la Antropología Cultural”, p. 335 .

5 Para ampliar la información sobre la conmemoración de los Centenarios de la Independencia en América Latina y en Colombia, véase Johnson, Death, dismemberment, and memory: body politics in Latin America Rincón, De Mojica, Gómez. Entre el olvido y el recuerdo. Iconos, lugares de memoria y cánones de la historia y la literatura en Colombia y Escobar, De Mojica, Maya, Conmemoraciones y crisis. Procesos Independentistas en Iberoamérica y la Nueva Granada.

6 Martínez, “Cómo representar a Colombia? De las exposiciones universales a la Exposición del Centenario, 1851-1910”, p. 330.

7 Rodríguez, "Cuerpos, honras fúnebres y corazones en la formación de la República colombiana", p. 157. 
Concordato de 1887 - a la paz, la unidad y la integridad del territorio, luego del fin de la Guerra de los Mil Días, saldada con la pérdida del istmo y de la ciudad de Panamá. La conmemoración de los centenarios de la Independencia nacional se fijó como meta la urgente necesidad de rehacer los fundamentos de la Patria y restablecer la unidad nacional, ${ }^{8}$ en el marco del gobierno del partido Conservador, periodo en la historiografía colombiana conocido como La Hegemonía Conservadora - 1886-1930 - . En todo el país, los centenarios estuvieron atravesados por esta reafirmación. No obstante, a diferencia de lo planteado por Ojeda y Barón, la conmemoración del centenario no fue sólo una repetición de lo sucedido en Bogotá el 20 de julio de 1910, ${ }^{9}$ cada región celebró a sus héroes y mártires tributando distintos honores y estableciendo complejos calendarios festivos que se prolongaron varios años y que otorgaban la legitimidad a los representantes del poder, como se aprecia en el caso de Tunja.

Desde el inicio de las conmemoraciones de las batallas de este imaginario independentista bañado en sangre de héroes ha existido abundante historiografía académica que se revisa con cada efeméride de las mismas. El tema ha sido constante fuente de estudio desde la creación de la academia nacional y las regionales de historia y de sus distintos órganos de difusión. El mito de los héroes de la Patria surgió como parangón de la identidad de aquella Nación unitaria, centralizada, que salía de la Guerra de los Mil Días. ${ }^{10}$ Luego de esto y durante mucho tiempo, e incluso ante las actuales conmemoraciones, los estudios de la historia académica tradicional y los centros de historia regionales acapararon los marcos explicativos del periodo, y el mito de la formación nacional permanecería incuestionable e intocable.

El papel de la Academia Colombiana de Historia en la celebración del centenario de la Independencia nacional giró en torno al estudio de los acontecimientos "con el fin de descubrir los aspectos moralizantes formativos en ella contenidos. Poniendo el énfasis en el uso de documentos como método para sacar la verdad a la luz. La academia se propuso fomentar la enseñanza de la historia para mantener vivo el imaginario patriótico y por la conmemoración de las efemérides patrias". ${ }^{11} \mathrm{El}$ texto clásico de estas celebraciones, ganador de medallas y concursos, fue el de Jesús María Henao y Gerardo Arrubla, ${ }^{12}$ primer texto de enseñanza de la historia patria y oficial de Colombia que permaneció vigente hasta la aparición de la Nueva Historia en los años sesenta del siglo XX.

\footnotetext{
$8 \quad$ Ojeda y Barón, "La conmemoración del héroe en el compendio de la Historia de Colombia de Jesús María Henao y Gerardo Arrubla (1910)”, p. 82.

$9 \quad$ Ibid., p. 83.

10 Para el caso de España y México véase: Chust, Mínguez, La construcción del héroe en España y México (1789-1847).

11 Rausch, La historia de Colombia (1910) por Henao y Arrubla ¿De qué manera, después de cien años, logró mantenerse vigente este tradicional relato histórico?, pp. 4-5.

12 Henao y Arrubla, Historia de Colombia para la enseñanza secundaria.
} 
La Academia Colombiana de Historia estableció relaciones explícitas con el Estado desde su fundación, pues la iniciativa fue promovida desde el Ministerio de Instrucción Pública de los gobiernos de la Hegemonía Conservadora. Los primeros miembros fueron nombrados mediante resolución oficial y sus funciones y metas fueron establecidas por el gobierno. La presencia mayoritaria del partido Conservador en los fundadores hasta la década de los treinta del siglo Xx, "mantuvo la idea de un proyecto patriótico suprapartidista que consideraba el pasado como objeto de veneración y no como objeto de estudio, como arte de anticuario y no como ámbito de investigación para comprender el presente". ${ }^{13}$

La historia, o más bien, la historia patria, como guía para la exaltación del héroe de la Independencia, ejemplo moral de la Nación, queda en manos de los miembros del recién constituido Centro de Historia de Tunja (1905), la mayoría conservadores y muchos de ellos curas, que llenaron y corrigieron más de mil páginas de lo que sería el guion del drama que representaría la sociedad boyacense en las fiestas patrias de los centenarios. ${ }^{14}$

Los discursos, los desfiles y lo que en ellos se representó, son los valores que esta sociedad, que no acababa de salir del siglo XIX, quiso representar en la segunda década del xx, mezclando en ellos, los tradicionales de la cultura literaria y educativa de la "Muy Noble y Muy Leal" ciudad colonial, con las aleccionadoras decisiones heroicas que los fundadores de la República tomaron un siglo atrás: ${ }^{15}$ la exaltación de los días más felices en los que Tunja volvió a ser la sede del poder, en ese caso federalista, los electores que declararon la Independencia absoluta de la provincia de Tunja para preservar y salvar a su católica sociedad de las amenazas del liberalismo doceañista de Cádiz; los átomos volando de Antonio Ricaurte, héroe en san Mateo; las balas y los huesos de los heroicos mártires boyacenses de la "Reconquista" y de "La Pola" y los ejecutados en Tenza; la sangre derramada en los "Altares de la Patria", lugares heroificados de la memoria nacional en las batallas libertarias de Vargas y Boyacá.

Hitos que se entrelazan fuertemente con el pasado hispánico de Tunja, acompañado de un muy notorio olvido del pasado indígena, manteniendo la memoria de la civilidad a partir de la fundación hispánica de la ciudad (1539), son los motivos alrededor de los cuales la conmemoración, la fiesta, el discurso, el poema, el desfile, la misa, la pintura, la escultura, las ofertas comerciales, los periódicos, el ornato, la urbanización, la higienización, la modernización, el

13 Rodríguez, Memoria y olvido: usos públicos del pasado en Colombia, 1930-1960, p. 42.

14 Los valores que representan estas celebraciones y los ancestros que reconocen vienen del culto a los héroes popularizado en las naciones americanas durante el siglo XIX. Earle, "Padres de la Patria and the Ancestral Past: Commemorations of Independence in Nineteenth- Century Spanish America", p. 788.

15 Tovar Zambrano, "Porque los muertos mandan. El Imaginario Patriótico de la Historia Colombiana", pp. 125-169. 
progreso, la civilidad y la felicidad, que marcan el despertar de la ciudad, tras cien años de acariciar las glorias de su lejano pasado.

En esta década de los centenarios ${ }^{16}$ se hicieron presentes dos tipos de conmemoraciones que intentaron hermanar, bajo la atenta dirección del guion oficial de la diócesis y la gobernación ${ }^{17}$ al Pueblo Boyacense, aquel que exalta a los héroes y a las instituciones tradicionales: de un lado están las celebraciones donde se conmemoraron hechos políticos: la Independencia nacional (1810), la Constitución de la República de Tunja (1811) y la Independencia absoluta de Tunja (1813) y aquellos donde se conmemoraron, como lo expresa Tovar Zambrano, a "los héroes del Panteón Nacional y el gran mito y culto del Libertador [Simón Bolívar]. [Revistiendo] a un personaje con las insignias de los muertos ilustres, procedimiento que arroja la representación del personaje en una imagen ideal, potenciada con las significaciones que provienen de unas tradiciones de pasados heroicos y de difuntos célebres" ${ }^{18}$, invocando a estos héroes venerados y martirizados para la protección de la Patria.

A esta última descripción corresponden los centenarios del nacido en la boyacense Villa de Leiva, Antonio Ricaurte y su muerte en san Mateo en 1814, ${ }^{19}$ de los mártires tunjanos de $1816^{20}$ - de cuyo centenario trata este texto-y los de la heroína Policarpa Salavarrieta, La Pola y los mártires de Tenza en 1817, que conmemoran a los héroes que aceptando la decisión heroica, sucumbieron trágicamente antes de lograr el objeto de su sacrifico y los que triunfaron en el

16 Al respecto de la década de los Centenarios en Tunja, hemos desarrollado los centenarios políticos de 1910 y 1911. Véase: Martinez, Otálora, "Patria y Madre Patria. Las fiestas centenarias de 1910 y 1911 en Tunja", pp. 115-143.

17 Para el caso del centenario de la independencia mexicana celebrado en ciudad de México, el régimen porfirista, en sus postrimerías, dirige e intenta relegitimar la última de las elecciones - y todo el régimen de hecho- de Porfirio Díaz (1910). Con este Centenario, el régimen buscó la identificación y la declaración como heredero directo de las tradiciones liberales de la insurgencia (independencia) y del benemérito Juárez (reforma) bajo los presupuestos de paz, orden y progreso como garantes de la inserción de México en el concierto de las naciones modernas. En el caso de Tunja se exponen los mismos valores, que en el caso de México son símbolos del régimen liberal, pero que en el de Boyacá son propios de la república conservadora con intervención directa de la iglesia. Véase: Guedea, Asedios a los Centenarios (1910 y 1921).

18 Tovar Zambrano, "Porque los muertos mandan. El Imaginario Patriótico de la Historia Colombiana", p. 130.

19 Perú de Lacroix, Diario de Bucaramanga o vida pública y privada del Libertador Simón Bolivar, p. 151.

20 Una vez restablecido Fernando VII en el trono, los ministros absolutistas deciden enviar contra la Capitanía de Venezuela y el Nuevo Reino de Granada, que se debatían desde 1810 en luchas políticas internas, a la fuerza armada de diez mil hombres conocida como Ejército Expedicionario de Costafirme, al mando de Pablo Morillo, el "Pacificador". Rápidamente esta fuerza logró restablecer el régimen monárquico, inaugurando el periodo clásico denominado la Reconquista, en la cual un tribunal de purificación condenó a muerte a los criollos involucrados en las primeras juntas independentistas. 
campo de batalla (Vargas y Boyacá) tras vencer a los maltrechos ejércitos del rey en $1819^{21}$ para fundar la República, y siguiendo a José Manuel Restrepo, dar vida a la Nación. ${ }^{22}$

Como afirma Hobsbawm, estas tradiciones inventadas asociadas con la Nación, los símbolos e historias patrias, se refieren al conjunto de prácticas regidas normalmente por reglas manifiestas o aceptadas tácitamente y de naturaleza ritual o simbólica, que buscan inculcar valores y normas de comportamiento por medio de la repetición, lo cual implica de manera automática una continuidad con el pasado — un pasado conveniente — para legitimar una serie de condiciones de la ficción política creada en unos ancestros. ${ }^{23}$ En el caso tunjano y en otros de estos centenarios independentistas en América, los ancestros y las tradiciones en forma de valores celebrados fueron los héroes de la independencia, por un lado, con unos valores (Independencia, libertad, paz, progreso y modernidad) y por otro, los conquistadores (lengua, religión, unión y civilidad). ${ }^{24}$

En estas fiestas centenarias, en donde desfilan todas las corporaciones civiles, militares y eclesiásticas, como lo expresa Deas, la élite tunjana, al igual que la bogotana. ${ }^{25}$ "Defendían la independencia, pero nunca repudiaron lo que España había hecho en América, y ellos ondeaban la lengua como una bandera", ${ }^{26}$ representando los valores que les eran tan caros como la hispanidad, que en Tunja no sólo significa la gramática, sino pulsar la lira en sus seculares concursos literarios.

La celebración de 1916, el más importante de los centenarios de los mártires, aquellos héroes irredentos que ante la disyuntiva heroica deciden sacrificar su vida, sus bienes y su familia a favor de la utopía ${ }^{27}$ entregándose por la Patria, son los conmemorados y ejemplarizantes significantes que se van a repetir en todos los discursos, poesías contrahechas, oraciones fúnebres, peregrinaciones

21 Tovar, "Porque los muertos mandan. El Imaginario Patriótico de la Historia Colombiana", pp. 132-135.

22 Véase: Restrepo, Historia de la Revolución de la República de Colombia, tomo III y IV y Colmenares, "La Historia de la Revolución en Colombia, por José Manuel Restrepo: una prisión historiográfica", pp. 7-23.

23 Hobsbawm, "Inventando tradiciones", pp. 3-15.

24 Al respecto de la puesta en escena de estos valores desde una perspectiva comparada, véase: Sánchez, "Dos representaciones, una misma Independencia: Las vistas cinematográficas de los festejos de los Centenarios en México, 1910 y 1921" y Lempérière, "Los dos Centenarios de la Independencia Mexicana (1910 y 1921). De la Historia Patria a la Antropología Cultural", pp. 317-352.

25 Véase: Pereira, "Cachacos y guaches: la plebe en los festejos bogotanos del 20 de julio de 1910”, pp. 79-108.

26 Deas, Del poder y la gramática y otros ensayos sobre historia, política y literaturas colombianas, p. 49.

27 Tovar Zambrano, "Porque los muertos mandan. El Imaginario Patriótico de la Historia Colombiana", pp. 125-169. 
cívicas, veladas literarias, misas campales, ordenanzas, decretos, artículos, libros centenarios, juntas organizadoras, programas y telegramas, que se les tributa durante el patriótico homenaje con que la ciudad de Tunja celebra:

El sacrificio de las victimas inmoladas en territorio boyacense, por orden del Pacificador Morillo durante la época del Terror [...], homenaje de respetuosa consideración y de profundo cariño a la memoria venerada de esta región de abnegados patricios, que en la segunda década del siglo XIX, ofrendaron con heroísmo sin medida su bienestar, su fortuna y hasta su propia existencia en aras de la Libertad, para legarnos Patria Grande y Feliz [...] cuya sangre vertida en los cadalsos, bajo la cuchilla y el plomo enemigos fue simiente fecunda de Héroes que en breve hizo florecer el árbol bendito de la Libertad en Colombia. ${ }^{28}$

El papel de la Historia Patria y la conservación y sacralización de las reliquias de los mártires y héroes de la Independencia dentro del proyecto de Nación de la "Hegemonía Conservadora", codirigido por la iglesia católica, es el objetivo central de este estudio de historia regional. Dentro de este mismo marco explicativo relata el único caso de la presencia y exaltación de restos óseos de los mártires de la Patria, que, si bien es común en otros países como México, resulta inusual en Colombia y Venezuela, donde sólo se habían sacralizado órganos como el corazón de Simón Bolívar en el siglo XIX. ${ }^{29}$ Por tanto, el caso de los Mártires de Tunja en 1916 es un antecedente precursor de la veneración de las reliquias en la República.

Gran parte de las obras que construyó y edificó la generación del Centenario para inaugurar la modernidad han sido destruidas; y mientras se celebran los bicentenarios no hay obra significativa ni hitos históricos; sólo permanecen sus discursos y ordenanzas que recuerdan que estas obras merecerían quizá mejor suerte. Este es el testimonio de la ciudad de Tunja en el espejo del centenario de 1916.

\section{La ciudad en espera del Progreso y la Fiesta}

La ciudad de Tunja tenía 8,407 habitantes en 1907, poco más que los 5,000 que el intelectual y político Manuel Ancízar registrara en su decimonónica "Peregrinación de Alpha" ${ }^{30}$ medio siglo antes. En la descriptiva elaborada por la gobernación, los autores concluyen con las expectativas que las líneas férreas y el mejoramiento de la carretera central del norte traerían para la ciudad: "La mejora de las vías de comunicación que convergen a la carretera 
nacional, así como las condiciones características de la situación geográfica y política de la ciudad y la índole misma de sus habitantes, concurrirán a mejorar y mantener su existencia económica y su condición de centro instruccionista y lugar apacible, sano y seguro para vivir; mayormente si la vía carretera se convierte en ferroviaria". ${ }^{31}$

Al final de la primera década del siglo $\mathrm{xx}$, los historiadores académicos Rubio y Briceño publicaron su premiado libro: Historia de Tunja (1909), cuyo último capítulo está dedicado a la Descripción de la Tunja Actual, ${ }^{32}$ donde consignaron el cambio de la ciudad colonial a la moderna a finales del siglo XIX; y manifestaron que la "ciudad española antigua ha mejorado notablemente", notándose la incipiente modernidad en la urbanización, en calles, andenes, empedrados y tres parques públicos; Tunja tiene 700 construcciones, además de contar con el banco de Boyacá, que no es otro que el banco del Lazareto; un teatro municipal, dos imprentas públicas, periódicos y seis establecimientos de educación secundaria, entre los que se cuenta una Escuela Normal de Varones, una de institutoras y el Colegio de Boyacá con su biblioteca y su gabinete de física y química que subsisten en parte, y que fueron dotados por el Estado Soberano de Boyacá al final del siglo XIX.

Los premiados historiadores afirman que moran en Tunja: "10.000 almas en pena sobreviviendo bajo techos derruidos y aleros desplomados", ${ }^{33}$ almas que presenciaron el arribo del presidente boyacense y general Rafael Reyes, quien llegó a Tunja procedente de Bogotá en el primer automóvil que se ve en la ciudad, en la primera década del siglo xx, ya que Tunja es atravesada por la carretera central que la une con Bogotá por el mismo camino real que la unía con Santafé. Varias empresas de transporte cubren las líneas a Bogotá en cinco horas de viaje y hacia la vecina Sogamoso, en tres horas. ${ }^{34}$

El poder de la iglesia seguía siendo inmenso como en los tiempos coloniales, sobre todo tras la firma del Concordato y la instalación de la silla diocesana en Tunja el 29 de julio de 1880, con la bula Infinitus Amor de León XIII. El obispo Maldonado Calvo controla gran parte de las actividades en el campo de la beneficencia al administrar, como en los tiempos coloniales, instituciones de salud como el hospital de caridad, el asilo, el ancianato y los fondos del Lazareto de Boyacá. Desde su baldaquino, Maldonado Calvo también dirige y pontifica sobre la vida política de la capital y del departamento de Boyacá.

En Tunja existen colegios privados, molinos de trigo y chircales para la elaboración de teja y ladrillo, como en tiempos coloniales. Las obras gubernamentales incluyen la reconstrucción de la casa de la Torre y la casa

31 Gobernación de Boyacá, Reseña histórica y descriptiva de la ciudad de Tunja y datos estadísticos del Departamento (Edición Oficial), p. 14.

32 Rubio y Briceño, Tunja desde su fundación hasta la época presente, pp. 324-351.

Ibid., p. 324

Triana, Revista de Colombia, volumen del Centenario, 1910. 
municipal, donde se aloja temporalmente la gobernación, ambas en la plaza de Bolívar.

La administración departamental funcionaba en el edificio de santo Domingo con el correo nacional, la imprenta, el archivo, la Biblioteca del Centenario y el museo inaugurados en 1910 y reinaugurados en 1913; el telégrafo funcionaba en una casa al frente del hospital de caridad ubicado en colonial convento de santa Clara la Real, atendido por las hermanas dominicas de La Presentación con su colegio contiguo. La penitenciaria ocupaba el claustro de san Agustín y la comandancia del batallón de veteranos, el de san Francisco; el colegio de Boyacá ocupaba el ex claustro jesuítico, que apenas sobrevive con las pocas rentas que recibe, viejos claustros coloniales que, en manos del Estado, completan el cuadro de la ciudad.

En 1906, el agua procedente de la quebrada de Barón llega a Tunja por primera vez, las pilas públicas de la Fuente chiquita y El Jordán, de propiedad particular, ${ }^{35}$ fueron arregladas y ornadas con motivo de los centenarios de 1910 y 1913, mientras que los tanques del acueducto eran inaugurados en las fiestas del centenario de 1910. La Compañía de Energía Eléctrica de Tunja inició su construcción en 1907 y las líneas de conducción y la maquinaria fueron instaladas en junio de 1909 para estar listas en el centenario de 1910.

En cuanto a los sitios de ornato, en la mitad de la plaza está un Bolívar pedestre rodeado de una verja elaborada en la Penitenciaria, una plazuela donde está la antigua fuente conocida como el Mono de la Pila, otra contigua a san Laureano, donde está la Plaza de los Mártires, al sur; y el arbolado parque Pinzón, al norte, frente a la penitenciaria. En el campo de Boyacá permanece el obelisco que la administración del Estado Soberano mandó construir en la década de los ochenta del siglo XIX. ${ }^{36}$ La mayoría de avenidas y camellones durante estas celebraciones fueron macadamizados. Desde 1907 se tenía proyectado el ferrocarril que iría hasta Santa Rosa de Viterbo y que es permanente referencia de los oradores de los centenarios y lo será hasta que en la década de los treinta llegue por fin el tren.

\section{“Si BoYACÁ HA SIDO CUNA DE HÉROES TAMBIÉN LO ES DE CIUDADANOS AGRADECIDOS"37}

Abigail Morales, párroco de la iglesia de santa Bárbara y miembro del Centro de Historia de Tunja, en cuya jurisdicción parroquial está la capilla de san

35 Gobernación de Boyacá, “Gaceta Departamental 77”, Tunja, abril 20 de 1910.

36 "Reseña histórica y descriptiva de la ciudad de Tunja, escrita por el Señor Doctor Don Dustano Gómez el año de 1907, por petición del Director General de Estadística Nacional, cuando el General Reyes fraccionó nuestro populoso Departamento", en Repertorio Boyacense 11, Tunja, 1913, pp. 573-586.

37 Centro de Historia de Tunja, Repertorio Boyacense 38, p. 61. 
Laureano y el paredón donde fueron hechas las ejecuciones de 1816, dirige una nota al presidente de la Asamblea Departamental porque se acerca la fecha en que la ciudad debe celebrar: "el centenario del sacrificio de sus eximios varones fusilados dentro de su recinto". 38

En 1916 el centro del ritual conmemorativo planteaba un problema fundamental por la conmemoración de la muerte de unos mártires que dieron su vida en defensa de la Patria, pasados por las armas por órdenes del Pacificador Morillo en su fugaz paso por Tunja, en los días finales de noviembre de 1816 durante la Reconquista. Sus cuerpos permanecían enterrados en fosa común al pie del altar de la cercana capilla de san Laureano, en la salida de la ciudad, contigua al lugar del acontecimiento. ${ }^{39}$

La cercana plazuela de los Mártires al costado norte de la capilla de san Laureano había cambiado de nombre en 1883 cuando dejó de recibir el del santo y con motivo del primer centenario del natalicio del Libertador en el Estado Soberano de Boyacá, pasó a llamarse de los Mártires, siendo bendecida por el obispo el 25 de julio de aquel año ${ }^{40} \mathrm{y}$ desde entonces lugar de frecuentes discursos. Desde 1903 la Asamblea había ordenado la construcción de un monumento, que en 1916 aún no había sido inaugurado. ${ }^{41}$

Siguiendo con la carta del párroco de santa Bárbara, Abigail Morales solicitaba, pese a la crónica falta de presupuesto que había afectado igualmente a las celebraciones anteriores, que la fiesta "revista la mayor solemnidad posible". ${ }^{42}$ Tunja se miraba en el espejo de la ciudad heroica de Cartagena de Indias, que había conmemorado el 24 de febrero de 1916 a sus nueve gloriosos mártires. En esta nota el presbítero Morales sugiere el 29 de noviembre como la fecha señalada para la celebración por ser "en aquel día el sacrificio de los tres más esclarecidos próceres, entre los siete que forman el Martirologio

38 García Samudio, La Reconquista de Boyacá en 1816, p. 135.

39 El viernes 29 de noviembre de 1816, día de mercado a las 10 de la mañana, es sacado de su casa José Cayetano Vásquez y llevado a la plaza mayor donde lo esperan sus dos compañeros de martirio: Juan Nepomuceno Niño y el teniente coronel José Ramón Lineros, presos en la casa de la Torre, donde esperaba la escolta del batallón expedicionario de La Victoria. Delante de cada uno de los presos iba un ataúd y los religiosos de san Francisco llevando - según Ramón C. Correa- el Cristo de su iglesia conventual que era sacado recurrentemente en Tunja durante las epidemias en la época colonial y republicana. Desde temprano había en San Laureano un piquete de infantería, los mártires atados a los banquillos fueron fusilados a redoble de tambor frente al muro conocido hoy como de los Mártires, un taco encendido en la gorguera de Niño incineró en parte el cadáver y al anochecer de aquel día fueron conducidos y enterrados en una fosa común de la cercana capilla de san Laureano. Rubio y Briceño, Tunja desde su fundación hasta la época presente, 168-169 pp. y Ramón C. Correa, "El santo Cristo de los mártires de Tunja", 1971, pp. 3407-3709.

40 Anónimo, "Plazuela de los Mártires", p. 591.

41 Rubio y Briceño, Tunja desde su fundación hasta la época presente, pp. 169-170.

42 García Samudio, La Reconquista de Boyacá en 1816, p. 135. 
Tunjano". ${ }^{43}$ Termina su nota diciéndole que puede contar con el apoyo del obispo, del Centro de Historia y de los estamentos educativos, mismos que han celebrado los anteriores centenarios y que: "se prestaran gustosos a esta fiesta de justicia y de gratitud" ${ }^{44}$ pidiendo a la Asamblea la constitución de una Comisión Centenaria.

Veinte días más tarde la Asamblea de Boyacá expidió la ordenanza 12 de 1916, por la cual se celebra un Centenario, considerando que "En ese año se cumple el Centenario en que fueron sacrificados en esta ciudad y en las poblaciones de Leiva, Sogamoso y Chita por orden del Pacificador Morillo [...] [unos mártires] y que es un deber de los pueblos agradecidos honrar la memoria de los que derramaron su sangre para legarles Libertad e Independencia" y ordenaba fijar el 29 de noviembre del mismo año para conmemorar el sacrificio de las víctimas del Terror, tanto en Tunja como en otras poblaciones del departamento, nombrando una Comisión de tres individuos, destinando 500 pesos oro para el cumplimiento de la ordenanza, que es firmada por el médico Silvino Rodríguez, presidente de la Asamblea. ${ }^{45}$

Casi cuatro meses después de ser creada por la ordenanza y faltando cuatro meses para la fecha señalada, el 24 de julio se instalaba la Junta del Centenario de los Mártires de 1816, integrada por el presbítero Abigail Morales, el médico Manuel R. Vásquez y don Agustín Morales Vargas, presididos por el gobernador Domingo A. Combariza. Su primera acción por unanimidad fue dirigir una nota al obispo de la diócesis solicitándole su valiosa colaboración y a los vecinos más connotados de cada una de las provincias: "Para que de acuerdo con sus habitantes se hagan representar en una procesión cívica al sitio del acontecimiento que se va a conmemorar, por medio de carros alegóricos", ${ }^{46}$ que distinguieran los valores y significantes que la élite quería darle a esta fiesta patria y el infaltable libro conmemorativo, que sería comprado al político y académico Nicolás García Samudio.

En efecto, el 17 de agosto de 1916, el secretario de la Academia Nacional de Historia, Pedro María Ibáñez, enviaba la felicitación por el libro: $L a$ Reconquista de Boyacá, al joven Nicolás García Samudio. Este texto editado en la imprenta del departamento y comprado con el dinero de la comisión, hacía parte de los libros centenarios que el Centro de Historia de Tunja realizaba para los festejos. ${ }^{47}$

En este centenario al que se habían invitado todas las provincias y que se celebraría en la fecha del martirio de los fusilados en la capital del departamento, los valores que propuso la Junta para ser representados por cada

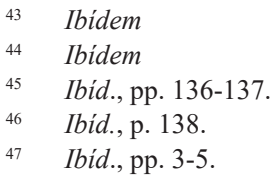


una de las provincias en el desfile, fueron: la historia, la gloria, el progreso, la fama, la conquista, el heroísmo, el patriotismo, el trabajo, la civilización, la paz, la libertad y la industria. La Junta Centenaria constituyó igualmente una comisión de señoras de la élite tunjana, presidida por la esposa del gobernador, "para que dispongan la manera como las damas de Tunja han de colaborar en la procesión cívica". ${ }^{48}$

A diferencia del anterior ciclo de centenarios políticos, la capital conmemoraba en esta ocasión el sacrificio de tunjanos mártires en un lugar definido de su estructura urbana, a diferencia del centenario de Antonio Ricaurte, a quien erigieron su estatua en el parque Próspero Pinzón al norte de la plaza de Bolívar. Esta vez el polo festivo urbano se ubicaba en el sur de la ciudad y existía la posibilidad cierta y documentada por el Centro de Historia de Tunja de encontrar y exhumar de la fosa común de la ermita de san Laureano, los restos de los mártires José Cayetano Vázquez ${ }^{49}$ y José Nepomuceno Niño, ${ }^{50}$ tunjanos y, el teniente coronel José Ramón Lineros,${ }^{51}$ natural de La Palma en el vecino departamento de Santander. De esta manera se otorgaba la corporeidad simbólica al acontecimiento a celebrar y sacralizarlos como parte del discurso martirológico de la Patria.

48 Centro de Historia de Tunja, Repertorio Boyacense 38, pp. 39-40. Los carros alegóricos representados en la peregrinación cívica el 29 de noviembre de 1916 en Tunja, tenían estos temas referenciados y asignados a cada una de las provincias que componen el Departamento de Boyacá.

49 José Cayetano Vásquez (Tunja, 1761-1816) hijo de un regidor español del cabildo de Tunja, estudio filosofía y jurisprudencia en Santafé. El 18 de octubre de 1811 fue elegido secretario de la Junta Suprema gubernativa de Tunja y capitán general y gobernador de la república de Tunja. En 1813 vuelve a ocupar el cargo de gobernador del estado hasta la entrada en la ciudad de las tropas del rey, pronunciando en su proclama a los tunjanos la frase símbolo de la fecha: "Eternamente vive quien muere por la Patria". Vásquez huye a Santafé donde es apresado y conducido a Tunja para ser fusilado. Rodríguez, Boyacenses en la Historia de Colombia, p. 65.

50 Juan Nepomuceno Niño (Tunja, 1769-Tunja, 1816) criollo, estudio derecho en Santafé. En 1812 fue elegido presidente civil gobernador de la república de Tunja por el colegio electoral. Se enfrentó en la guerra civil a Nariño y tomada Tunja tuvo que firmar los tratados de paz de Santa Rosa de Viterbo en que los estados de Tunja y Cundinamarca pactaron un armisticio. Derrotado finalmente por Antonio Nariño y los centralistas se retiró a su hacienda, hasta la llegada de las tropas del rey a la provincia, cuando es apresado y enviado a prisión en la casa de la Torre hasta su fusilamiento. Rodríguez, Boyacenses en la Historia de Colombia, p. 62.

51 José Ramón Lineros (Palmas del Socorro-Tunja, 1816), criollo, teniente coronel de milicias y teniente de gobernador de la provincia de El Socorro. En 1816 huyó derrotado por los españoles a los llanos del Casanare. Confiado en un pasaporte que le garantizaba salvoconducto para regresar a El Socorro, es apresado y conducido a la casa de la Torre en Tunja hasta su fusilamiento. Camacho, “coronel José Ramón Lineros Ilustre Prócer Santandereano", pp. 1569-1572. 


\section{De la ignominiosa fosa A la CATEdRAL}

La mañana del martes 19 de septiembre de 1916, dentro de las actividades de la Junta del Centenario de los Mártires de 1816, el secretario Agustín Morales Vargas y el alcalde de Tunja, general Santiago Brigard, se trasladaron con cuatro reclusos de la Penitenciaría a la ermita de san Laureano..$^{52}$

Entre el altar y el púlpito los penitenciarios buscaban la fosa común en donde habían sido enterrados los mártires el 29 de noviembre de 1816; entonces encontraron una fosa de 1.5 metros de profundidad que contenía cinco cadáveres, tres de los cuales estaban en un estrato superior, los dos cuerpos del estrato inferior, según concepto del doctor Vázquez, fueron descartados porque parecían ser los de una mujer y un niño y estaban separados por una espesa capa de tierra.

Por la tarde se reanudaron las labores de exhumación con la presencia de los miembros de la Junta, Abigail Morales y Manuel R. Vásquez; posteriormente llegaron el presidente del consejo municipal, el médico Escipión Cárdenas y el médico y político Silvino Rodríguez, Jorge Simón Ortega y el gobernador Combariza. Los doctores Vásquez y Cárdenas "verificaron la clasificación y reconocimiento de los huesos de los cuales resultaron seis fémures en buen estado, seis tibias; seis radios; seis cúbitos; seis húmeros; dos clavículas; dos fragmentos de peroné y una vértebra cervical; fragmentos de tres cráneos y varios huesos pequeños de las extremidades", el presbítero Morales entonó un responso una vez verificado el acto y la Junta puso en manos del presidente del consejo municipal los restos descubiertos para que esta corporación: "acordara lo conveniente acerca de la custodia y conservación de tan valiosas reliquias". ${ }^{53}$

Estos restos exhumados — que pertenezcan o no a los mártires del 29 de noviembre - en aquellas fiestas del centenario otorgaba legitimidad a las instituciones que encabezaban la celebración, siendo el vínculo que los unía, tras cien años, con los héroes de la Nación a través de la historia. Los valores que simbolizaban para la sociedad tunjana de 1916 están a punto de desfilar, ya están presentes e incorporados sus restos humanos como reliquias, ${ }^{54} \mathrm{se}$ les puede ver y venerar. Tunja se dispone entonces a hacer misa campal,

52 Según Ramón C. Correa, la capilla de san Laureano permaneció cerrada desde que los agustinos recoletos la abandonaron en 1729, siendo consagrada nuevamente por el obispo Maldonado Calvo el 1 de abril de 1917. Correa, "La iglesia de San Laureano de Tunja", pp. 3079-3081.

53 García Samudio, La Reconquista de Boyacá en 1816, pp. 40-42.

54 "Llamamos reliquias a los vestigios venerados de personas, que son consideradas objeto de exaltación. Puede tratarse de sus cuerpos, huesos o de sus cenizas”. En México el discurso político desde el siglo XIX, se caracterizó por ver en sus héroes las mismas características que se atribuían a los santos, y así sus vestigios recordarían sus virtudes. La mayoría de héroes de la insurgencia en México fueron martirizados, los que les daba sin duda una connotación de religiosidad patria muy grande. Vázquez, "Las Reliquias y sus Héroes”, pp. 48-49. 
público homenaje, desfile, exposición, velada literaria y a colocarlos dentro del recinto que guarda los restos de los fundadores hispánicos de la ciudad colonial dándole identidad a esta vieja urbe indiana, su antigua iglesia Mayor de Santiago, convertida en Catedral. ${ }^{55}$

\section{La Misa Campal del 29 de noviembre}

A las ocho y media de la mañana del 29 de noviembre de 1916 el Repertorio Boyacense relata cómo una "inmensa multitud de todas las clases sociales", acudió ante el muro de adobe al sur de Tunja, donde habían sido sacrificados los héroes-mártires Vásquez, Niño y Lineros. En ese sitio se había levantado un templete de madera para cubrir el muro ya derruido, en frente del cual se colocó un improvisado altar en cuya parte superior se ubicó la urna en que fueron depositados los huesos exhumados. La Junta Patriótica de boyacenses residentes en Bogotá envió unas placas de mármol para ser colocadas en esta ceremonia. ${ }^{56}$

Con presencia del obispo Maldonado, el deán de la catedral celebró la misa de réquiem y a continuación fue cantado un melancólico De Profundis; el miembro de la comisión, promotor y párroco de la vecina santa Bárbara pronunció la oración fúnebre: "Hermanos míos, y permitidme que os llame hermanos, porque al pie del altar de la patria, todos somos hermanos", haciendo un sinnúmero de referencias a los héroes de la antigüedad grecorromana y bíblica; fulminando al público con versos leídos en latín, rememorando las luchas de la Independencia, describiendo poéticamente el hecho:

Se oyen las detonaciones de las descargas, y aquellos tres esclarecidos varones, glorias purísimas de esta Heroica ciudad y de la población de Las Palmas, volaron a los cielos a recibir la corona de los mártires y escalaron la inmortalidad para brillar en ella con refulgente resplandor como soles de primera magnitud" [terminando con una característica propia de estos centenarios y es la reconciliación con el pasado colonial de la ciudad]: "Para honrar santamente la Memoria de nuestros mártires, enviemos a la Madre España un abrazo de olvido y un ósculo de perdón, y sacrifiquemos generosos en el Altar de la Patria nuestros viejos rencores; la Patria, la Patria antes que todo; sobre la Patria solo Dios [...] porque como dijo el mártir José Cayetano Vásquez: Eternamente vive quien muere por la Patria. ${ }^{57}$

55 En el caso de los héroes insurgentes de la independencia de México véase: Mejía Madrid, "Ahí van mis restos: Los cuerpos del Héroe".

56 Centro de Historia de Tunja, Repertorio Boyacense 38, pp. 62-70.

$57 \quad$ Ibid., pp. 52-53. 


\section{De la exposición en el Panóptico o la industria PENITENCIARIA}

A las diez y media de la mañana, y luego de los latinajos propinados por el presbítero Morales en el paredón de los mártires, la fiesta se traslada al norte, en donde la Penitenciaría es abierta al público para presenciar "la hermosa exposición de artefactos construidos por los presos de ese establecimiento en los talleres de hilados y tejidos de fique, carpintería, ebanistería, mecánica y fundición, zapatería, guarnicionería y cantería", el gobernador inauguró la exposición y una biblioteca para el precinto. ${ }^{58}$

El director del establecimiento, Juan Ángel, dio el correspondiente discurso en el que exaltó el avance de la penitenciaría: "de la disciplina, del progreso y el buen nombre de esta casa de fama tradicional". En ese día se inauguraron el taller, las nuevas instalaciones de la dirección, la biblioteca y una botica. Durante la década de los centenarios los presos de esta penitenciaría habían trabajado en las obras públicas de la ciudad de manera gratuita; por orden del gobierno nacional dada unos meses antes a la celebración del centenario de 1916, se había suscrito un contrato para que 80 presos siguieran trabajando por 144 pesos oro al mes, valor que era girado por el departamento a la penitenciaría. Una vez elogiado el establecimiento, Ángel habla del papel de éste en el progreso industrial de Boyacá: "Estos talleres son una esperanza para el departamento, que tanto necesita de industriales y obreros, y más cuando tenemos la buena nueva de que pronto oiremos en esta ciudad el pito y la campana de la locomotora y tras ella los carros que nos traerán las máquinas y los elementos que necesitamos para la industria y llevarán nuestros productos a otras regiones".

El ideal de progreso e industria es celebrado en un presidio, el mismo director al inicio de su discurso lo señala: "Parece una paradoja que un presidio esté celebrando el Centenario de los mártires de la libertad, pero no debemos sorprendernos porque a ellos que aspiran a la libertad [...] y si saben aprovecharse aprendiendo un oficio, después irán, pasados por el crisol de estas penas, con méritos para el cielo". ${ }^{59}$ Los presos de la penitenciaría continuarán sirviendo de mano de obra de todos los proyectos urbanos emprendidos en la década, sin que el pago les sea reconocido directamente, realizando todas las obras de la modernidad de la ciudad. Acabados los centenarios en 1919, aún se esperaba en Tunja y se anhelaba en los discursos el vapor de la locomotora del progreso.

$59 \quad$ Ibid., pp. 96-103. 


\section{Peregrinación cívica}

A la una de la tarde comenzó en la plaza de Bolívar la peregrinación cívica en dirección al parque de los mártires donde se inauguraba una verja de hierro hecha en los talleres de la penitenciaría, y posteriormente volviendo al atrio de la catedral por la actual carrera novena rebautizada entonces como Juan Nepomuceno Niño.

En la procesión cívica, "que fue una espléndida demostración de cultura y gusto artístico, estuvieron representadas casi todas las provincias del departamento, aparte de otras entidades por carros alegóricos vestidos con lujo y elegancia, los cuales iban precedidos por sendos pabellones, que eran conducidos cada uno por una señora y varias señoritas de nuestra distinguida sociedad, presididos por la banda de música del departamento". ${ }^{60}$

Seguidos de señoritas tunjanas portadoras de coronas de margaritas en honor a los mártires, los representantes de los departamentos y del Congreso nacional, los descendientes de los próceres, el obispo Maldonado Calvo, el Capítulo catedralicio, el clero secular y regular, el gobernador del departamento, los secretarios del despacho, los empleados civiles y cerrando el desfile la banda militar y el batallón Soublette, mientras que el carro alegórico de la república, a cargo del banco de Boyacá, no salió por un grave daño mecánico en esta época de la modernidad y el progreso.

La procesión donde iban los miembros del Consejo Municipal en el carro con la urna que contenía los huesos exhumados en septiembre de 1916, la Fábrica de Hilados y Tejidos de Samacá y la colonia de chiquinquireños residentes en Tunja ofrecieron las coronas de margaritas y las colocaron al pie del muro donde fueron sacrificados los héroes-mártires; así el rito y recordación de su sacrificio quedaba completo. Luego en la plaza de los mártires, llevaron la palabra Nicolás García Samudio, en representación de la Cámara de Representantes y de la Academia Nacional de Historia; el presidente del Concejo Municipal, el médico Escipión Cárdenas y el gobernador de Boyacá, quien suspendió su discurso por la lluvia.

García Samudio ponderaba en su discurso el pasado colonial de la ciudad y su participación en la Independencia entre frecuentes alusiones a la antigüedad clásica; finaliza su intervención diciendo: "En este día de dolorosas recordaciones para Tunja, precisa evocar la memoria de estos próceres y pedir para ellos la Gloria [...]. Pidámosla por la sangre vertida en este muro, respetado milagrosamente por el tiempo; divinizado ahora por las bellas y virtuosas damas tunjanas que han venido a cubrirlo de flores inmarchitables, y consagrado para siempre por la gratitud de la República". ${ }^{61}$ 
Vuelta la procesión a la Catedral en la plaza de Bolívar, se verificó el último acto de la peregrinación cívica que terminó al frente del atrio de la iglesia mayor, conclusión del religioso rito patrio rendido a los mártires. Con llovizna y en medio de los cantos de los seminaristas que entonaban el Himno Nacional, ${ }^{62}$ solemnemente una comisión de señores notables introducía y depositaba en la catedral la urna con los restos de los mártires para que desde allí sus reliquias protegieran al Pueblo Boyacense. En este altar descansarían y velarían en paz y en perpetua memoria los héroes-mártires de Tunja.

\section{¡OH MáRTIREs! En la EXPOSICIÓN DE PINTURA Y LA VELADA LITERARIA}

Los juegos florales con los que Tunja rindió homenaje a los mártires de 1816 fueron dedicados a exaltar los valores literarios y de civilidad de la capital, eventos que recuerdan el legado hispánico y funden los hechos reconocidos en este centenario como génesis de la ciudad, la tradición hispánica de la conquista, la colonia y la Independencia.

En el salón del recientemente estrenado teatro municipal, el gobernador inauguró "una lúcida exposición artística de alumnos y alumnas de la Academia de Pintura y Dibujo", pasteles, óleos y dibujos eran la antesala del evento lírico literario de la noche en que se cerraba la celebración del centenario; en este evento no sólo se premiaron los cuadros, sino también los marcos, pues una de las participantes fue premiada con cuadros para sus marcos y fueron entregados diplomas para las mejores pinturas al óleo y al pastel. ${ }^{63}$

Por la noche, en el mismo teatro, se llevó a cabo la velada lirico-literaria organizada por el Centro de Historia, donde se leyeron poesías a los mártires de 1816 y se alternó con música de orquesta, además de rendir los discursos: "Hoy después de 100 años, vuestros hijos un homenaje a tributaros vienen, y un gajo de laurel Tunja os envía y os bendice, falange luminosa de Mártires sublimes que por fosa tenéis el alma de la Patria mía". ${ }^{64}$

Roberto Vargas Tamayo, poeta tunjano, también participa en esta velada con su poesía "Flores del Martirio": " $¡$ Con sangre de los Mártires las balas dejaron aquel suelo en sangre tinto, pero también rompiéronle las alas al Águila Imperial de Carlos V [...] Caín!... Caín!... ¿Qué has hecho de ese hermano cuya sangre también era española? [...] es Cristo que en perdón a todos baña; y

62 Es claro que existía también dentro de estas celebraciones patrias un objetivo pedagógico dirigido a los jóvenes, que pudieran encontrar en estos próceres el ejemplo de amor por la Patria, para más información ver. González, Ceremoniales, fiestas y nación. Bogotá: Un escenario, p. 325.

63 Centro de Historia de Tunja, Repertorio Boyacense 38, pp. 55-56, 103-104.

64 Ibid., pp. 77-80. 
- para unirlas con eternos lazos - la Cruz del Sur sus luminosos brazos extiende sobre América y España". ${ }^{65}$

Hay rememoraciones a todos los héroes de todas las épocas y las naciones para hacer ver que el culto a los mártires creaba una identidad nacional, en el discurso de Nebardo Rojas, por ejemplo, se lee:

Héroes Divinizados tuvo la infortunada patria de las Ciencias y de las Artes (...); Guillermo Tell ennoblece la Historia y se lleva tras sí toda nuestra admiración y nuestro entusiasmo porque personifica 'la justa cólera de un hombre libre'; y hoy, la Virgen Guerrera de Domremy [Juana de Arco] sostiene y alienta con el cálido fulgor de su recuerdo las energías de una Nación que se desangra y padece en la persecución de un ideal", igualmente el discurso de perdón y olvido para con España es nuevamente sostenido: "Para honra de la raza, arrojemos un velo sobre la materialidad de las escenas que en aquellos días de ira pudieron presenciar los sencillos moradores de Tunja, la Heroica, y como acertado tributo de amor a la memoria de tan preclaras victimas la promesa de olvido y de perdón para los sacrificadores. ${ }^{66}$

El siglo XIX es recordado como falto de progreso, y esta época de principios del siglo Xx, como la oportunidad de alcanzar la modernidad tantas veces postergada por el carro de Marte, tal como lo pronuncia Ernesto Murillo:

Cantemos a la Diosa de la Paz, la cual, de Olivo, coronada, blanca como la nieve y gigantesca, a modo de Jesús, recorre nuestros campos y florestas acentuando en el pecho colombiano la unión de los diversos territorios; el odio por las guerras fratricidas; el amor al trabajo, y el impulso a contribuir en la apertura de vías que no nos mantengan alejados en la difusión de conocimientos, comunión del alma nacional. ${ }^{67}$

Finalmente, en Tunja es recibido el telegrama en que el Senado de la República expedía la Ley 52 del 28 de noviembre de 1916, por la cual se rinde un tributo de gratitud a los mártires de la Patria fusilados en 1816, y se ordena destinar la suma de 5.000 pesos del Tesoro Nacional para erigir un monumento en uno de los parques de Bogotá y otro en Tunja con la inscripción: "Año de 1916. Colombia agradecida a los mártires de 1816". ${ }^{68}$ Contrastando esta suma con los 500 pesos oro destinados por el gobierno departamental, siempre en premuras financieras. Con esta velada lírico- literaria culminan las solemnidades patrióticas del Centenario de los Mártires el 29 de noviembre de 1916 en Tunja, mientras en una urna los presuntos huesos de los héroesmártires reposaban ya en la Catedral de la ciudad.

\footnotetext{
Ibid., pp. 86-91.

Ibid., pp. 92-93.

Ibid., p. 83.

Ibid., pp. 104-105.
} 


\section{Conclusiones}

Una de las finalidades de la celebración oficial de Tunja y su década de los centenarios fue mostrar ante propios y ajenos una imagen precisa de la Nación y de la comunidad regional del Pueblo Boyacense, el cual honraba en fechas tan emblemáticas a sus libertadores, a sus héroes, a sus mártires. Por ello se apeló al ejercicio de un poder simbólico mediante el imaginario social, en varias piezas efectivas que la gobernación y la diócesis utilizaron de manera eficaz y fundamental, controlando la vida colectiva y garantizando el ejercicio del poder político que fue legitimado en estos actos. ${ }^{69}$

Este régimen dual utilizó la memoria a manera de conmemoración política y discurso histórico, organizando las referencias al pasado en función de las agendas del poder. ${ }^{70} \mathrm{La}$ historia, instrumentalizada, busca generar los sentimientos que identifiquen a esta comunidad política en función de los valores y las tradiciones de las que esta historia los hace herederos. La narrativa de esta historia positivista y evolucionista, en la que el motor es el progreso, está a cargo de la institución que escriben este discurso y articulan dos pasados del espacio urbano - el colonial y el de la independencia - como los orientadores del porvenir, el antiguo Centro de Historia de Tunja (1905), filial regional de la Academia Colombiana de Historia y que en 1946 se convirtió en la actual Academia Boyacense de Historia.

Los espacios festivos de esta década de los centenarios generan una memoria y en este caso particular, alrededor del centenario de los mártires de 1816, el mito del héroe-mártir genera también mitos fundadores de la nacionalidad en Tunja. El uso ideológico que hace la élite política y religiosa de la ciudad y el departamento de los huesos exhumados de los héroes, les otorga a su vez a estos actores sociales legitimidad ante el régimen político nacional y los consagra como herederos de la tradición — les otorga la genealogía - que se recorporiza en los restos mostrados en la urna y paseados por el recinto urbano.

El hecho de sacarlos de una capilla abandonada y exhibirlos a la pública veneración para colocarlos finalmente en la catedral de la capital, marca a su vez de toda la identidad colectiva de la ciudad, pues pretendía consagrarlos como Héroes-mártires y colocarlos al lado de los conquistadores-fundadores del pasado hispánico, desde donde ejercerían su protección. Luego del fin de la Hegemonía Conservadora, y durante las celebraciones de las fundaciones de las principales ciudades hispánicas en el territorio de la actual Colombia, fueron 
usuales los traslados y conmemoraciones de los cuerpos de los conquistadores españoles con presencia de la Academia Nacional de Historia y de la Iglesia Católica, como el caso del Adelantado Gonzalo Jiménez de Quesada, fundador de Santafé de Bogotá, cuyos restos fueron trasladados del cementerio central a la Catedral Primada de la ciudad ${ }^{71}$ en el IV Centenario de la fundación (1938). En Tunja fue notable la construcción del mausoleo en la Catedral de los restos del fundador de la ciudad, Gonzalo Suárez Rendón, para el IV Centenario de la fundación (1939) y del soldado, cura y poeta de la conquista Juan de Castellanos, ambos reubicados dentro de la Catedral, en donde por demás reposan todas las primeras generaciones de los conquistadores encomenderos de los siglos coloniales, cuya morada de eterno descanso es compartida aún por estas dos genealogías.

A su vez, al colocarlos en el espacio máximo de la iglesia católica de esta diócesis se dejaba en claro cuáles eran los poderes ya no de la conquista, sino de aquella república reinventada y regenerada en el discurso de los héroes de la Independencia. Así mismo, el sector sur de Tunja - a partir de la plaza de Bolívar - se urbanizará desde la década de los centenarios con la construcción de estas plazas y parques, siendo desde entonces el sector con mayor número de construcciones y monumentos republicanos.

De los héroes-mártires de 1816, Tunja sólo guarda memoria de Vásquez y Niño, pero tampoco debe olvidarse a miembros de la élite tunjana y criollos, quienes intentan simbolizar dentro del imaginario centralista y unitario al resto de héroes-mártires fusilados en ese mismo año en villas y pueblos de la antigua provincia. El hecho de no ser natural de Tunja ni de Boyacá ha generado que se invisibilice la existencia de Lineros, quien compartió paredón, fosa y urna con los mártires tunjanos.

Durante las dos primeras décadas del siglo XXI, y tras celebrar pobremente el bicentenario, el Paredón de los Mártires y los bustos de Vásquez y Niño, así como el bosque de la República y la columna de la Plaza de los Mártires padecen el más cruel abandono y olvido. El nombre de Niño fue impuesto a un viaducto que une a la vieja con la nueva Tunja; el de Vásquez es usado desde finales del siglo XIX para demarcar un territorio que uniría a la ciudad con el río Magdalena, mientras que el rastro de la urna donde se guardan las reliquias

71 En el caso mexicano, cuando se produce el traslado de los restos de los héroes insurgentes a la Catedral de ciudad de México, muy temprano, en septiembre de 1823, la tumba del conquistador Hernán Cortés en el cercano Hospital de Jesús, tuvo que ser escondida para evitar que sus restos fueran exhumados y quemados. Para Rueda, es claro que más que un ajuste de cuentas, significa que los independentistas tendrían una genealogía insurgente, queriendo separar los recientes hechos de la Independencia del pasado novohispano. Rueda, "El descuido de los Héroes. Apuntes sobre historiografía marginal”, pp. 64-69. 
se ha perdido nuevamente en el inmenso espacio de las criptas de la colonial Catedral de Tunja. ${ }^{72}$

\section{Bibliografía}

\section{Fuentes Primarias}

Ancízar, Manuel, Peregrinación de Alpha, Bogotá, Biblioteca Banco Popular, 1984.

Anónimo, "Plazuela de los Mártires", Repertorio Boyacense 11, 1913, pp. 591-593.

Centro de Historia de Tunja, Repertorio Boyacense 38, Tunja, Imprenta del Departamento, 1916.

García Samudio, Nicolás, La Reconquista de Boyacá en 1816, Tunja, Imprenta del Departamento, 1916.

Gobernación de Boyacá, Reseña histórica y descriptiva de la ciudad de Tunja y datos estadísticos del Departamento (Edición Oficial), Tunja, Imprenta del Departamento, 1907.

Gobernación de Boyaca, Gaceta Departamental 77, Tunja, Imprenta del Departamento, abril 20 de 1910.

Gómez, Dustano, "Reseña histórica y descriptiva de la ciudad de Tunja, escrita por el Señor Doctor Don Dustano Gómez el año de 1907, por petición del Director General de Estadística Nacional, cuando el General Reyes fraccionó nuestro populoso Departamento", Repertorio Boyacense 11, 1913, pp. 573-586.

Perú de Lacroix, Luis, Diario de Bucaramanga o vida pública y privada del Libertador Simón Bolivar, Medellín, Bedout, 1964.

Restrepo, José Manuel, Historia de la Revolución de la República de Colombia tomos III y IV, Medellín, Bedout, 1969.

Rubio Ozias y Briceño Manuel, Tunja desde su fundación hasta la época presente, Bogotá, Imprenta Eléctrica, 1909.

Triana Miguel, Revista de Colombia, volumen del Centenario, Bogotá, 1910.

72 En 1823, México realiza las primeras exhumaciones de los restos óseos de los insurgentes para llevarlos a través de grandes ceremonias a la catedral de la ciudad de México. El trasegar de los huesos de estos héroes a finales del xIX e inicio del xx, los llevarían finalmente a la columna de la Independencia, inaugurada en las celebraciones del centenario en 1910 — verdadero canto de cisne del régimen Porfirista-, convertida en 1925 en el gobierno de Plutarco Elías Calles, una vez asentada la Revolución, en el altar de una patria renovada pero sostenida y sobre todo protegida aun por las reliquias de los héroes en su nuevo sitio de reposo, la Columna de la Independencia, desde donde La Revolución se hacía su heredera. Vázquez, "Las Reliquias y sus Héroes", p.110. En el caso de Tunja se tuvo una idea similar desde finales del siglo xIX cuando se levantó el obelisco en el campo de la batalla de Boyacá, aunque se construyó el monumento y la cripta, nunca se trasladaron las reliquias de los héroes a este lugar. Martinez, Otálora, "La memoria de tanto inmortal. El campo de Boyacá 18192015 ", p. 41. 


\section{Fuentes Secundarias}

Anderson, Benedict, Comunidades imaginadas. Reflexiones sobre el origen y la difusión del nacionalismo, México, Fondo de Cultura Económica, 1993.

Baczko, Bronislaw, Los imaginarios sociales. Memorias y esperanzas, Buenos Aires, Nueva Visión, 1991.

Camacho, Calixto, "Coronel José Ramón Lineros Ilustre Prócer Santandereano", Repertorio Boyacense 227-228, 1963, pp. 1569-1572.

Chust, Manuel, Mínguez, Víctor (eds.), La construcción del héroe en España y México (1789-1847), Universitat de Valencia, 2003.

Colmenares, Germán (ed.), "La Historia de la Revolución en Colombia, por José Manuel Restrepo: Una prisión historiográfica”, La Independencia: Ensayos de His-toria Social, Cali, Instituto Colombiano de Cultura, Colección Popular, 1986, pp. 7-23.

Correa, Ramón C., "La iglesia de san Laureano de Tunja", Repertorio Boyacense 258259, 1969, pp. 3079-3081.

, "El santo Cristo de los mártires de Tunja", Repertorio Boyacense 266-267, 1971, pp. 3704-3709.

Deas, Malcolm, Del poder y la gramática y otros ensayos sobre historia, política y literaturas colombianas, Bogotá, Tercer Mundo, 1993.

Earle, Rebecca, "Padres de la Patria and the Ancestral Past: Commemorations of Independence in Nineteenth-Century Spanish America", Journal of Latin American Studies, vol. 34, núm. 4, 2002, pp. 775-805.

Escobar, Juan, De Mojica, Sarah, Maya, Adolfo (eds.), Conmemoraciones y crisis. Procesos Independentistas en Iberoamérica y la Nueva Granada, editorial Javeriana, Bogotá, 2012.

González, Marcos, Ceremoniales, fiestas y nación. Bogotá: un escenario, Intercultura, Bogotá, 2012.

Guedea, Virginia (coord.), Asedios a los Centenarios (1910 y 1921), México, Fondo de Cultura Económica e IIH-UNAM, 2009.

Henao Jesús María y Arrubla, Gerardo, Historia de Colombia para la enseñanza secundaria, Librería Colombia-Camacho Roldán \& Tamayo, 2 vols., Bogotá, 1920.

Hobsbawm, E.J., "Inventando tradiciones”, Historias 19, 1988, pp. 3-15.

Johnson, Lyman, Death, dismemberment, and memory: body politics in Latin America, Albuquerque: University of New Mexico Press, 2004.

Lempérière, Annick, "Los dos Centenarios de la Independencia Mexicana (1910-1921): de la Historia Patria a la Antropología Cultural", Historia Mexicana vol. XLV, núm. 2, 1995, pp. 317-352.

Martinez, Abel y Otálora, Andrés, "Patria y Madre Patria. Las fiestas centenarias de 1910 y 1911 en Tunja", Historia y Memoria 5, 2012, pp. 115-143.

"La memoria de tanto inmortal. El campo de Boyacá 1819-2015", Nuevas Lecturas de Historia, núm. 34, 2015, pp. 19-91.

Martínez, Fréderic, “¿Cómo representar a Colombia?, De las exposiciones universales a la Exposición del Centenario, 1851-1910”, en Gonzalo Sánchez y María Emma Wills (comps.), Museo, Memoria y Nación, Bogotá, IEPRI Universidad 
Nacional de Colombia, ICANH, Museo Nacional de Colombia, Ministerio de Cultura, 2000.

Mejía Madrid, Fabricio, "Ahí van mis restos: Los cuerpos del Héroe", Proceso Bicentenario, núm. 1, 2009.

Ojeda, Ana Cecilia y Barón Vera, Alejandra, "La conmemoración del héroe en el compendio de la Historia de Colombia de Jesús María Henao y Gerardo Arrubla (1910)", Historia Caribe, núm. 10, 2005, pp. 79-95.

Pereira Fernández, Alexander, "Cachacos y guaches: la plebe en los festejos bogotanos del 20 de julio de 1910", Anuario Colombiano de Historia Social y de la Cultura, vol. 38, núm. 1, 2011, pp. 79-108.

Rausch, Jane, La historia de Colombia (1910) por Henao y Arrubla ¿De qué manera, después de cien años, logró mantenerse vigente este tradicional relato histórico?, Tunja, Universidad Pedagógica y Tecnológica de Colombia, 2011.

Rincón, Carlos, De Mojica, Sarah, Gómez, Liliana (eds.), Entre el olvido y el recuerdo. Iconos, lugares de memoria y cánones de la historia y la literatura en Colombia, Bogotá, editorial Javeriana, 2010.

Rodríguez, Gustavo, Boyacenses en la Historia de Colombia, Bogotá, Jurídicas Wilches, 1994.

Rodríguez, Pablo, "Cuerpos, honras fúnebres y corazones en la formación de la República colombiana", Anuario Colombiano de Historia Social y de la Cultura, núm. 38, 2011, pp. 155-179.

Rodríguez, Sandra, Memoria y olvido: Usos públicos del pasado en Colombia, 19301960, Universidad Nacional de Colombia, Universidad del Rosario, Bogotá, 2017.

Rueda, Salvador, "El descuido de los Héroes. Apuntes sobre historiografía marginal", Historias, núm. 75, 2010, pp. 64-69.

Sánchez Cabello, Erika, "Dos representaciones, una misma Independencia: las vistas cinematográficas de los festejos de los Centenarios en México, 1910 y 1921 ”, Independencias-dependencias-interdependencias, Toulouse, VI Congreso CEISAL, 2010.

Tovar Zambrano, Bernardo, "Porque los muertos mandan. El Imaginario Patriótico de la Historia Colombiana", en Carlos Miguel Ortiz y Bernardo Tovar Zambrano (eds.), Pensar el Pasado, Universidad Nacional de Colombia, Facultad de Ciencias Hu-manas, Departamento de Historia y Archivo General de la Nación, Bogotá, 1997, pp. 125-169.

, "La Historiografía Colonial", Departamento de Historia (coord.), La Historia al final del Milenio. Ensayos de historiografía colombiana y latinoamericana, Editorial Universidad Nacional, 1995, Bogotá, pp. 21-117.

Vázquez, María del Carmen, "Las Reliquias y sus Héroes", Estudios de Historia Moderna y Contemporánea de México, núm. 30, 1995, pp. 47-110. 